\title{
Review: $\beta$ sitosterols improve urinary symptoms in the short term in men with benign prostatic hyperplasia
}

Wilt T, Ishani A, Mac Donald R, et al. Beta-sitosterols for benign prostatic hyperplasia. Cochrane Review, latest version 19 July 1999. In: the Cochrane Library. Oxford: Update Software.

QUESTION: In men with benign prostatic hyperplasia (BPH), are $\beta$ sitosterols effective for improving urinary symptoms?

\section{Data sources}

Studies were identified by searching Medline (1966 to July 1998), EMBASE/Excerpta Medica (1974 to July 1998), Phytodok, the Cochrane Library, and bibliographies of relevant studies and by contacting authors.

\section{Study selection}

Studies were selected if they were randomised controlled trials (RCTs) of $\beta$ sitosterol treatment for $\geqslant 30$ days in men with symptomatic BPH.

\section{Data extraction}

2 reviewers independently assessed the quality of study methods and extracted data on patients, intervention, and outcomes (urological symptom scores, urodynamic measures, mean urine flow, residual urine volume, nocturia, and changes in prostate size). Missing or additional data were obtained from authors. Differences were resolved by discussion.

\section{Main results}

4 double blind, placebo controlled RCTs that involved 519 men (mean age 65 y) met the selection criteria. Trial duration ranged from 4 to 26 weeks, and overall follow up was $92 \% .3$ RCTs used non-glucosidic $\beta$ sitosterol, 60 to $195 \mathrm{mg}$ /day, and 1 RCT used $100 \% \beta$ sitosteryl $\beta$ D glucoside. $\beta$ sitosterols led to greater improvement in urological symptom scores, nocturia, peak urine flow, mean urine flow, and residual volume than did placebo

Source of funding: no external funding.

For correspondence: Mr R Mac Donald, General Internal Medicine (111-0), Minneapolis VA/VISN

13 Center for Chronic Diseases Outcomes

Research, 1 Veterans Drive, Minneapolis, MN 55417, USA. Fax +16127251964 . $\beta$ sitosterols $v$ placebo for benign prostatic hyperplasia*

\begin{tabular}{lll} 
Outcomes at 4 to 24 wk & $\begin{array}{l}\text { Number } \\
\text { studies }\end{array}$ & $\begin{array}{l}\text { Weighted mean } \\
\text { difference }(95 \% \mathrm{Cl})\end{array}$ \\
\hline IPSS scores & 2 & $-4.9(-6.3$ to -3.5$)$ \\
\hline Boyarsky QoL score & 1 & $-4.5(-6.0$ to -3.0$)$ \\
\hline Nocturia (times/evening) & 1 & $-1.0(-1.8$ to -0.3$)$ \\
\hline Peak urine flow $(\mathrm{ml} / \mathrm{s})$ & 4 & $3.9(0.9$ to 6.9$)$ \\
\hline Mean urine flow $(\mathrm{ml} / \mathrm{s})$ & 1 & $2.6(1.3$ to 3.9$)$ \\
\hline Residual volume $(\mathrm{ml})$ & 4 & $-28.6(-41.4$ to -15.8$)$ \\
\hline *IPSS = International Prostate Symptom Scale; QoL = quality of life
\end{tabular}

(table). Groups did not differ for prostate size or adverse effects.

\section{Conclusion}

In men with benign prostatic hyperplasia, $\beta$ sitosterols lead to short term improvement in urinary symptoms.

\section{COMMENTARY}

The meta-analysis by Wilt and colleagues is based on 4 small placebo controlled RCTs of purified plant sterol extracts ( $\beta$ sitosterols) derived from the genus Hypoxis (South African star grass), Pinus, or Picea. These agents, which are widely prescribed in Europe, have clinically important short term benefits for urinary flow and obstructive symptoms.

Saw palmetto, a botanical agent that is biochemically distinct from $\beta$ sitosterol, is more widely used in the United States and was shown to have similar clinical benefits in a recent systematic review of 18 RCTs by the same authors. ${ }^{1} \mathrm{~A}$ recent in vitro study suggests that saw palmetto, but not $\beta$ sitosterol, may have $\beta 1$ adrenergic blocking properties.

The challenge for clinicians is to advise their patients about the risks and benefits of these 2 families of phytotherapeutic compounds compared with those of $\alpha 1$ adrenergic blockers, such as terazosin, and $5 \alpha$ reductase inhibitors, such as finasteride. 2 studies comparing saw palmetto with finasteride (summarised in the JAMA review') suggest that their short term effects on symptoms and urinary flow are similar but that saw palmetto causes less erectile dysfunction.

We still lack essential information about the long term effects of the agents and how to use them alone or in combination. We do know that these plant based derivatives (saw palmetto extract, US $\$ 20 / \mathrm{mo}$ ) are much less expensive than finasteride $(\$ 82 / \mathrm{mo})$ or terazosin $(\$ 49 / \mathrm{mo})$.

Peter S Millard, $\mathrm{MD}, \mathrm{PhD}$

Clay Triplehorn, $D O$ Family Practice Residency Program Bangor, Maine, USA

1 Wilt TJ, Ishani A, Stark G, et al. Saw palmetto extracts for treatment of benign prostatic hyperplasia: a systematic review. JAMA 1998;280:1604-9. Erratum. 1999;281:515.

2 Goepel M, Hecker U, Krege S, et al. Saw palmetto extracts potently and noncompetitively inhibit human alpha 1 adrenoceptors in vitro. Prostate. 1999;38:208-15. 